\title{
Recent results of cetuximab use in the treatment of squamous cell carcinoma of the head and neck
}

This article was published in the following Dove Press journal:

OncoTargets and Therapy

28 August 2009

Number of times this article has been viewed

\author{
Francesco Perri' \\ Francesco Longo ${ }^{2}$ \\ Franco lonna ${ }^{2}$ \\ Francesco Caponigro' \\ 'Head and Neck Medical Oncology \\ Unit, ${ }^{2} \mathrm{Head}$ and Neck Surgery Unit, \\ National Tumor Institute of Naples, \\ Naples, Italy
}

Correspondence: Francesco Caponigro National Tumor Institute of Naples (Fondazione G Pascale), via Mariano Semmola, 80I3I Napoli, Italia

Tel +3908I 5903362

Fax +390815903822

Email caponigrof@libero.it

\begin{abstract}
Cetuximab is a chimeric monoclonal antibody that targets the epidermal growth factor receptor. The role of cetuximab is paramount in several subsets of head and neck cancer. In particular, the EXTREME study has indicated cetuximab as the only drug to improve survival when associated with cisplatin and 5 -fluorouracil in patients with recurrent/metastatic disease. Furthermore, cetuximab, both alone and in combination with cisplatin, is active in patients with recurrent/metastatic disease who have failed prior platinum-based chemotherapy. Cetuximab, given in association with radiation therapy, is a treatment of choice in first-line therapy of patients with locally advanced inoperable disease. In the same setting, the role of induction chemotherapy has gained considerable interest over the last few years and a number of efforts are being pursued to optimally integrate induction chemotherapy with radiation therapy plus cetuximab. The combination of cetuximab and other targeted therapies is among the most promising new perspectives for patients with head and neck cancer.
\end{abstract}

Keywords: cetuximab, head and neck cancer, locally advanced, recurrent/metastatic

\section{Introduction}

Epithelial growth factor receptor (EGFR) is a member of the ErbB family of receptors which are composed of an extracellular ligand-binding domain, a hydrophobic transmembrane segment and an intracellular tyrosine kinases domain. After ligand binding, homodymeric or heterodymeric complexes are formed which activate in turn the tyrosine kinase domain and downstream effectors. ${ }^{1}$ Squamous cell carcinoma of the head and neck (SCCHN) represents a suitable tumor in which anti-EGFR therapy can be explored due to nearly ubiquitous EGFR expression and its prognostic value. EGFR plays a critical role in SCCHN growth, invasion, metastasis and angiogenesis, ${ }^{2}$ and the mean EGFR levels in tumors are considerably higher than in normal tissue. ${ }^{3}$ High EGFR copy number detected by fluorescence in situ hybridization (FISH) has been shown to be a poor prognostic indicator. ${ }^{4}$ A similar study, ${ }^{5}$ including 134 patients with diagnosis of SCCHN, demonstrated that aberrant EGFR copy numbers, evaluated by quantitative real-time polymerase chain reaction (Q RT-PCR), is also associated with a poor clinical outcome. In both of the studies, the increased EGFR copy number does not correlate with the protein expression levels. Recently, the role of any EGFR gene polymorphism was explored in several human epithelial neoplasms including SCCHN. These polymorphisms [nucleotidic substitution G/A in the 497 codon of the exon 13 (R497K); 216G/T substitution in SP1 region of the promoter; CA dinucleotidic repetitions in the intron 1] seem to increase gene EGFR expression and correlate with a poor prognosis. ${ }^{6}$ 


\section{Cetuximab}

Cetuximab (Erbitux, C225) is a human-murine chimeric immunoglobulin $\mathrm{G}(\mathrm{IgG})$ monoclonal antibody that competitively binds to the extracellular domain of EGFR and prevents binding by the natural EGFR ligands, the main of which are EGF and transforming growth factor-alpha (TGF- $\alpha$ ). Among the entire panel of murine anti-EGFR antibodies, monoclonal antibody C225 was chosen for further clinical development for several reasons: it binds to the receptor with better affinity than the natural ligand; moreover, it also induces dimerization and downregulation of the EGF receptor which prevents further receptor binding and activation by the ligand. Potential clinical efficacy of cetuximab appears to involve multiple mechanisms, including inhibition of cell cycle progression, induction of apoptosis, inhibition of angiogenesis, inhibition of metastasis, and enhancement of the response to chemotherapy and radiation therapy. ${ }^{?}$

A phase I study of cetuximab was run by Baselga and colleagues who evaluated the pharmacokinetics and toxicity of cetuximab in 56 patients with advanced epithelial tumors over-expressing EGFR. ${ }^{7}$ Cetuximab was administered alone as a single dose in 14 patients, alone as weekly multiple doses in 17 patients and as weekly multiple doses in combination with cisplatin in 22 patients. Doses in the range of 200 to $400 \mathrm{mg} / \mathrm{m}^{2}$ were associated with complete saturation of systemic clearance. Cetuximab infusion was well tolerated at the dose level tested and the most commonly reported toxicities were fever, asthenia, transaminase elevation, and skin toxicity.

Another similar phase Ib study ${ }^{8}$ has evaluated safety, pharmacokinetics and activity of cetuximab in combination with cisplatin in patients with advanced SCCHN. Twelve patients who had high levels of EGFR expression and tumors easily accessible for repeated biopsies (pretherapy, 24 hours after first C225 infusion, 24 hours before third C225 infusion) were entered at three different dose levels of C225 with a fixed dose of cisplatin. Both of the above studies indicated a loading dose of $400 \mathrm{mg} / \mathrm{m}^{2}$ with a weekly maintenance dose of $250 \mathrm{mg} / \mathrm{m}^{2}$ as the dose schedule to be recommended for further studies. Skin toxicity was the most common adverse event occurring in $70 \%-80 \%$ of patients, but it was rarely treatment limiting.

The aim of this review is to present and discuss the current and future role of cetuximab in the different subsets of SCCHN.

\section{Recurrent/metastatic squamous cell carcinoma of the head and neck}

Chemotherapy is the treatment of choice for recurrent/ metastatic disease in patients not suitable for further surgery or irradiation. Cisplatin is the most used drug in this setting and the combination of cisplatin and 5-fluorouracil (5FU) has represented the mainstay of first line treatment for the last twenty years. Several drugs have been used in combination with cisplatin and/or 5FU with the attempt to improve results. ${ }^{9}$

The taxanes have been shown to be active in SCCHN mainly in combination with cisplatin, but this activity has to be balanced against the mostly overlapping toxicity profile (in particular myelotoxicity and neurotoxicity). The combination of cisplatin and cetuximab has been studied in first line treatment of recurrent/metastatic disease. In particular, in the phase Ib study run by Shin and colleagues, ${ }^{8}$ treatment was feasible and hints of antitumor activity was observed. Burtness and colleagues ${ }^{10}$ carried out a phase III trial where 117 patients with recurrent/metastatic SCCHN were randomly assigned to receive cisplatin $100 \mathrm{mg} / \mathrm{m}^{2}$ every four weeks with weekly cetuximab or placebo. Progression-free survival (PFS) was not statistically different between the two treatment groups. In particular, median PFS was 4.2 months for patients treated with cisplatin plus cetuximab and 2.7 months for patients treated with cisplatin plus placebo $(\mathrm{p}=0.09)$. Median overall survival (OS) was also not statistically different between the two groups; (9.2 and 8.0 months, $\mathrm{p}=0.21)$. Response rate was $26 \%$ and $10 \%$ in the two arms, respectively $(p=0.03)$. Patients treated with cisplatin and cetuximab experienced more frequently grade $3 / 4$ toxicity which was mostly due to cisplatin. As expected, skin toxicity was more frequent in the experimental arm (37.7\%) than in the control arm $(23 \%)(p<0.001)$. The issue of combining cetuximab with platinum (cis or carbo) and 5FU in recurrent metastatic disease was first addressed by Bourhis and colleagues in 53 patients. A substantially higher incidence of serious adverse events were observed in the cisplatin group $(67 \%)$ than in the carboplatin group (32\%); overall response rate was $36 \%$ and disease control rate was $74 \%$, with no substantial difference between cisplatin and carboplatin. In the entire population time to tumor progression (TTP) was 155 days and median survival was 297 days. ${ }^{11}$ This study paved the way to phase III evaluation. The EXTREME study, a phase III study comparing cisplatin-5FU with or without cetuximab, has provided evidence of statistically significant advantage in terms of locoregional control and overall survival for the experimental arm. In particular, median PFS was 5.6 months in the experimental arm and 3.3 months in the control arm $(\mathrm{p}<0.001)$. Overall survival was 10.1 months vs 7.4 months in the experimental and in the control arm, respectively $(\mathrm{p}=0.04)$. Overall response 
rate was $36 \%$ vs $20 \%$ in the experimental and control arm, respectively $(p<0.01)$. As for toxicity, no differences in the grade $3 / 4$ adverse events were recorded in the two arms. ${ }^{12}$

The prognosis for patients progressing after cisplatin containing regimen is very poor, with less than $5 \%$ response rate. On this basis, cetuximab has been tested in this setting.

Herbst and colleagues ${ }^{13}$ conducted a phase II trial in 131 patients who had obtained a stable disease (SD) or a progressive disease (PD) after a platinum-based chemotherapy. The combination of cetuximab and cisplatin was given to these patients who were divided into three subgroups: patients that had obtained a SD (SD cohort), patients that had obtained a PD after two cycles of CT (PD1 cohort) and patients that had obtained a PD after three or more cycles of CT (PD2 cohort). The objective response rate was $18 \%$ for the SD cohort, $20 \%$ for the PD1 cohort and $6 \%$ for the PD2 cohort. The median duration of response was 7.4 months for the SD cohort, 4.2 for the PD1 cohort and 4.1 for the PD2 cohort. Median overall survival for SD cohort was 11.7 months. The most common grade 3 and 4 cisplatin toxicities were myelosuppression and nephrotoxicity but there was no indication that cisplatin-based toxicity was exacerbated in combination with cetuximab, which induced the appearance of skin rash in $70 \%$ of patients.

Baselga and colleagues ${ }^{14}$ conducted a multicenter phase II trial of the combination of cetuximab and platinum therapy in patients with platinum-refractory SCCHN. Partial response $(\mathrm{PR})$ and disease control rate was $10 \%$ and $53 \%$, respectively. Median time to progression and overall survival were 72 and 150 days, respectively.

In patients who achieved a PR, the median TTP was 185 days and OS was 272 days. In addition, the median TTP and median OS were longer in patients receiving the three-week cycle compared with patients receiving the fourweek-cycle. Skin reactions and acne-like rash occurred in $80 \%$ of patients, but only $3 \%$ of patients experienced a grade $3-4$ cutaneous rash. This study demonstrated that the combination of cisplatin and cetuximab has a good activity in this population of platinum-refractory SCCHN patients and the results were particularly encouraging in view of the fact that more than half of the patients had received more than two cycles of platinum-based chemotherapy as first-line therapy.

The results of these two trials suggested that cetuximab given in association with cisplatin might have a role in reversing platinum resistance.

Moreover, cetuximab is effective also when given alone in patients with platinum-refractory SCCHN. In fact, Vermorken and colleagues ${ }^{15}$ tested single-agent cetuximab in a group of 103 patients with SCCHN that had progressed after a platinum regimen. No patients achieved complete response, $13 \%$ of patients achieved a partial response while the disease control rate was $46 \%$. The median TTP was 70 days and OS was 178 days. Progressive patients were switched to the cetuximab/cisplatin combination. In these patients, no objective responses were recorded but $27 \%$ of patients had a stable disease.

Cetuximab has been associated also to taxanes in patients with recurrent/metastatic disease. The combination of weekly docetaxel and standard cetuximab induced a 20\% partial response rate and a $47 \%$ disease control rate in 45 patients. ${ }^{16}$ Paclitaxel was also evaluated in combination with platinum and cetuximab and a significant tumor response rate $(56 \%)$ was observed. ${ }^{17}$

\section{Locally advanced inoperable squamous cell carcinoma}

Radiation therapy has been the treatment of choice in this subset of patients for several decades. ${ }^{9}$ However, clinical evidences now exist in favor of combined treatment approach, which includes chemotherapy and radiation therapy. In fact, several randomized trials have shown that adding concurrent chemotherapy to radiation significantly increases locoregional control. Furthermore, a recent meta-analysis reported an $8 \%$ increase in five-year survival with the combined approach. ${ }^{18}$ The common standard for chemotherapy in combination with radiation is cisplatin given at the dose of $100 \mathrm{mg} / \mathrm{m}^{2}$. However, the combined administration of chemo and radiation therapy is significantly more toxic than radiotherapy alone, both in terms of acute toxicities (mucositis, dermatitis, leucopenia, emesis) and delayed toxicities (feeding tube dependence, pharyngeal and laryngeal dysfunction). Furthermore, the combined administration of chemo- and radiotherapy compromises postoperative adherence to further treatments ${ }^{19}$ and is associated with more frequent and longer treatment interruptions than radiation therapy; in turn, delays in radiation therapy delivery can adversely affect patient outcomes. ${ }^{19}$

It is well known that tumor cell repopulation during treatment is implicated as a cause of treatment failure after primary radiotherapy. ${ }^{20}$ However, several studies have reported that repopulation of epithelial tumor cells after exposure to radiation is related to the activation and expression of EGFR. ${ }^{21-22}$ These findings suggest that EGFR blockade may be important in reducing tumor cell repopulation after radiotherapy and this strategy may improve tumor control. 
Several preclinical studies have investigated the effect of combined $\mathrm{C} 225 /$ radiation treatment in cell lines derived from human SCCHN. ${ }^{23}$ Such combined treatment resulted in a strong decrement in cellular proliferation. Saleh and colleagues demonstrated that, in cell lines derived by human SCCHN, addition of $\mathrm{C} 225$ to radiation treatment was able to inhibit cellular proliferation by approximately $35 \%$ for the lowest EGFR expressing cell lines and by $70 \%$ for the highest expressing cell lines. ${ }^{24}$

A phase I trial of cetuximab and radiation therapy was carried out at the University of Alabama. ${ }^{25}$ Thirteen of 15 patients achieved a complete response whereas a partial response was seen in the remaining two patients. Median duration of response was 28 months and toxicity data highlighted the safety of this approach without the need of dose modification. Recently Bonner and colleagues published a phase III trial comparing radiotherapy alone with the combination of cetuximab and radiotherapy in locally advanced inoperable SCCHN (424 patients). The experimental arm showed a statistically significant superiority in locoregional control and overall survival; in particular, duration of locoregional control was 24.4 months with combined treatment and 14.9 months $(p=0.005)$ in the control arm. Median survival time was 49 months in the experimental arm and 29.3 months in the control arm $(p=0.03)$; median PFS was 17.1 months and 12.4 months in the two arms respectively $(p=0.006)$. Cetuximab did not worsen the main toxicities associated to radiotherapy. ${ }^{26}$ Quality of life (QoL) in these patients was assessed by Curran and colleagues ${ }^{27}$ in a follow-up analysis in which QoL was assessed using two different questionnaires, the European Organization for Research and Treatment of Cancer (EORTC) QLQ-C30 which evaluates functioning and symptoms common to most cancer patients, and the QLQ HeN35 which evaluates symptoms specifically associated with head and neck cancer and its treatment. Compliance with completion of QoL questionnaires was high in both arms and, most importantly, there was no significant difference in QoL scores between the two treatment arms.

Cetuximab is now approved for use in combination with exclusive radiation treatment in patients with diagnosis of locally advanced inoperable SCCHN.

The following logical step was to combine cetuximab with radiation therapy and chemotherapy. Pfister and colleagues ${ }^{28}$ conducted a phase II study of a combined regimen of weekly cetuximab administered with conventional schedule and associated to standard cisplatin and radiotherapy. A total of 22 patients were enrolled in the study. Mucositis, skin rash, nausea, and vomiting were the main observed toxicities.
This study was closed early because of five serious adverse events including two deaths, one myocardial infarction, one bacteremia, and one atrial fibrillation. Three complete responses and 13 partial responses were observed in the 16 assessable patients. Three-year PFS and overall survival rate were $56 \%$ and $76 \%$, respectively. However, this regimen was not recommended for further evaluation due to heavy toxicity. Similar results were reported by Merlano and colleagues. ${ }^{29}$ The response rate was $100 \%$, but impressively high toxicity was reported with particular regard to skin toxicity. Kuhnt and colleagues ${ }^{30}$ evaluated the combination of concomitant hyperfractionated accelerated radiotherapy (HART) with cisplatin and cetuximab. Fourteen patients were treated and a response rate of $91 \%$ was achieved. The treatment was well tolerated and weekly cisplatin at the dose of $40 \mathrm{mg} / \mathrm{mg}^{2}$ was recommended in combination with cetuximab plus HART.

The role of induction chemotherapy in patients with locally advanced inoperable disease has gained considerable interest in the last two years with the publication of two phase III trials of docetaxel, cisplatin, 5FU vs cisplatin, 5FU. The first study was carried out by the EORTC. ${ }^{31}$ Patients were randomized to receive four cycles of either TPF (docetaxel and cisplatin $75 \mathrm{mg} / \mathrm{m}^{2}$ on day one, $5 \mathrm{FU}$ $750 \mathrm{mg} / \mathrm{m}^{2} /$ day, for five days of continuous infusion) or standard PF (cisplatin $100 \mathrm{mg} / \mathrm{m}^{2}$ on day one, $5 \mathrm{FU}$ $1000 \mathrm{mg} / \mathrm{m}^{2}$ daily for five days of infusion). Radiation therapy was subsequently administered. PFS was higher in the experimental arm (11.0 vs 8.2 months, $\mathrm{p}=0.007)$. Median overall survival was 18.8 months vs 14.5 months (hazard ratio $=0.73$ ). Response rate was also significantly higher in the experimental arm $(68 \%$ vs $54 \%, \mathrm{p}=0.006)$. Complete response rate was $9 \%$ vs $6 \%, p=n . s)$. Although neutropenia, as expected, was more frequent in the TPF arm, the toxic death rate was $2.3 \%$ in the TPF arm and 5.3\% in the PF arm. Quality of life was also better in patients in the TPF arm $(p=0.01)$. The second phase III study was carried out by Posner and colleagues. ${ }^{32}$ The treatment plan was very similar to the other study and three cycles of TPF (docetaxel $75 \mathrm{mg} / \mathrm{m}^{2}$, cisplatin $100 \mathrm{mg} / \mathrm{m}^{2}$ on day one, $5 \mathrm{FU} 1000 \mathrm{mg} / \mathrm{m}^{2}$ daily for four days of continuous infusion) were compared with three cycles of standard PF. Radiation therapy was administered for seven weeks and was combined with weekly carboplatin therapy. Overall survival was higher in the TPF group (71 vs 30 months, respectively; $p=0.006)$; locoregional control was also better in the TPF group $(\mathrm{p}=0.04)$. Overall response rate favored the experimental arm ( $72 \%$ vs $64 \%)$, but the difference was 
not significant. These two studies have represented a major breakthrough and have provided evidence that induction chemotherapy followed by irradiation can represent the best option in many cases. The next step is how to optimally integrate induction chemotherapy with cetuximab therapy in order to further improve treatment outcome by giving patients all the most effective therapeutic options in first line of treatment.

Kies and colleagues ${ }^{33}$ reported a study of induction chemotherapy with weekly paclitaxel, carboplatin and cetuximab in patients with inoperable disease. Complete response rate, which was the main endpoint of the study, was observed in $83 \%$ of 47 evaluable patients at the primary site and in $27 \%$ at the nodal site. Hematologic and skin toxicities were the only observed grade $3 / 4$ adverse events. The Eastern Cooperative Oncology Group (ECOG) has evaluated the combination of cetuximab, paclitaxel and carboplatin followed by cetuximab, carboplatin and radiation therapy in patients with locally advanced SCCHN. A high rate of complete pathological responses at the tumor site was observed; in particular 40/63 patients were clinical responders at week 8 after induction therapy. Among these, $63 \%$ of patients had complete pathological response at week 14 after chemoradiotherapy. Grade 4 neutropenia was the main adverse event being observed in $14 \%$ of patients. ${ }^{34}$ Tishler and colleagues have recently presented a phase I study of cetuximab added to TPF induction chemotherapy. This was conceived as phase I study because of 5FU escalation in association with standard doses of docetaxel, platinum and cetuximab. Preliminary results showed 11 partial responses out of 15 evaluable patients. $850 \mathrm{mg} / \mathrm{m}^{2}$ was the 5FU selected dose. ${ }^{35} \mathrm{~A}$ retrospective analysis of addition of cetuximab to induction TPF has been performed by Kuperman and colleagues. Standard doses of the four drugs were used; overall response rate was $71 \%$ in 21 enrolled patients; the toxicity profile was foreseeable and mild. ${ }^{36}$ Argiris and colleagues have recently reported a phase II study of neoadjuvant docetaxel, cisplatin and cetuximab followed by concurrent radiation, cisplatin and cetuximab in locally advanced SCCHN. The overall response rate to induction chemotherapy was $86 \%$ in 37 evaluable patients. After the combined chemoradiotherapy the overall response rate was $100 \%$. Hematologic and skin toxicities were the most relevant adverse events also in this study. ${ }^{37}$ Langer and colleagues have presented preliminary data of the ECOG 3303 study in which concurrent radiotherapy, cisplatin and cetuximab was given to 61 patients. The overall response rate was only $48 \%$ in this study. Moreover, a number of relevant adverse events including a death from neutropenic fever were observed. ${ }^{38}$ Bonnin and colleagues administered induction TPF (docetaxel $75 \mathrm{mg} / \mathrm{m}^{2}$ on day 1, cisplatin $75 \mathrm{mg} / \mathrm{m}^{2}$ on day 1 and fluorouracil $750 \mathrm{mg} / \mathrm{m}^{2}$ on day $1-5$, to be repeated every 21 days for 3 cycles) followed by concurrent chemoradiotherapy (cisplatin or cetuximab) in 123 patients with unresectable SCCHN. The overall response rate was $96 \%$ after induction chemotherapy, but subsequent chemoradiotherapy turned out to be very toxic showing a $64 \%$ of grade $3-4$ toxicity. ${ }^{39}$

Taken as a whole, these data show that appropriate integration of cetuximab, radiotherapy and induction chemotherapy have the possibility to improve treatment outcome in the near future. The results of completed and ongoing studies of cetuximab in the different subsets of patients with SCCHN are summarized in Tables 1 and 2.

\section{New perspectives}

The importance of cetuximab in the therapeutical armamentarium against SCCHN has considerably increased. The concomitant use of chemoradiotherapy and cetuximab has not matched the expectation, but its role is being revisited.

The Radiation Therapy Oncology Group (RTOG) is running a phase III randomized trial of chemoradiotherapy vs chemoradiotherapy plus cetuximab in patients with stage III/IVa squamous cell carcinoma of the oropharynx, hypopharynx or larynx. After stratification by site of primary, performance status, regional nodes, patients are to receive cisplatin conventional dose plus accelerated radiotherapy and concomitant boost with or without the addition of cetuximab at the common dose schedule.

Evaluation of cetuximab in the adjuvant setting is a further way to explore the potential of this compound. RTOG is running a randomized trial in locally advanced resected patients judged at high risk of relapse. Patients are randomized to receive radiation therapy plus cetuximab plus weekly cisplatin in the arm A and radiotherapy plus cetuximab plus weekly docetaxel in the arm B. On the other hand, another phase III trial is being conducted in patients with intermediate risk of relapse. Patients are randomized to receive either radiation therapy alone or cetuximab plus radiation therapy. Preliminary results are not yet available for each of the two studies; however, they are eagerly awaited since they are going to provide information on the possible usefulness of cetuximab also in the adjuvant setting.

An appealing new strategy involves the combination of different EGFR-targeted therapies, ie, the combined administration of a monoclonal antibody and a tyrosine 
Table I Completed clinical trials with cetuximab in SCCHN

\begin{tabular}{|c|c|c|c|c|c|c|}
\hline Trial & N. patients & Phase & Design & Endpoints & Results & Setting \\
\hline \multirow[t]{3}{*}{${\text { Burtness et } \mathrm{al}^{10}}$} & 117 & III & CDDP-cetuximab $^{\mathrm{a}}$ & OS & Not significant & First-line \\
\hline & & & vs & PFS & Not significant & Recurrent/metastatic \\
\hline & & & CDDP & ORR & Significant $(p=0.03)$ & \\
\hline \multirow[t]{2}{*}{ Bourhis et al"I } & 53 & ॥ & CDDP-5FU-cetuximab & ORR & $36 \%$ & First-line \\
\hline & & & & & & Recurrent/metastatic \\
\hline \multirow[t]{3}{*}{ Vermorken et $\mathrm{al}^{12}$} & 442 & III & CDDP-5FU-cetuximab ${ }^{a}$ & OS & Significant $(p=0.04)$ & First-line \\
\hline & & & vs & PFS & Significant $(p=0.001)$ & Recurrent/metastatic \\
\hline & & & CDDP-5FU & ORR & Significant $(p=0.001)$ & \\
\hline \multirow[t]{3}{*}{ Herbst et $\mathrm{al}^{13}$} & 132 & ॥ & CDDP-cetuximab & ORR & $12,8 \%$ & Second-line \\
\hline & & & & & & (Platinum-refractory) \\
\hline & & & & & & Recurrent/metastatic \\
\hline \multirow[t]{3}{*}{ Baselga et $\mathrm{al}^{14}$} & 96 & ॥ & CDDP-cetuximab & ORR & $10 \%$ & Second-line \\
\hline & & & & & & (Platinum-refractory) \\
\hline & & & & & & Recurrent/metastatic \\
\hline \multirow[t]{3}{*}{ Vermorken et al ${ }^{15}$} & 96 & II & Cetuximab & ORR & $13 \%$ & Second-line \\
\hline & & & & & & (Platinum-refractory) \\
\hline & & & & & & Recurrent/metastatic \\
\hline \multirow[t]{3}{*}{ Bonner et $\mathrm{a}^{26}$} & 424 & III & Radiotherapy-cetuximab ${ }^{\mathrm{a}}$ & PFS & Significant $(p=0.005)$ & Locally advanced disease \\
\hline & & & vs & OS & Significant $(p=0.003)$ & \\
\hline & & & Radiotherapy & ORR & Significant $(p=0.02)$ & \\
\hline \multirow[t]{4}{*}{ Pfister et $\mathrm{a}^{28}$} & 21 & ॥ & Radiotherapy-CDDP & ORR & $94 \%$ & Locally advanced disease \\
\hline & & & + cetuximab $^{\mathrm{a}}$ & & & \\
\hline & & & vs & & & \\
\hline & & & Radiotherapy-CDDP & & & \\
\hline
\end{tabular}

Notes: ${ }^{\text {Experimental arm. }}$

Abbreviations: OS, overall survival; PFS, progression free survival; ORR, overall response rate.

kinase inhibitor. A sound preclinical rationale for this approach does exist. In fact, while monoclonal antibodies require an intact EGFR ligand binding domain, tyrosine kinase inhibitors are also active against mutated forms of the EGFR. Furthermore, monoclonal antibodies can also elicit antibody-dependent cellular cytotoxicity. Matar and colleagues $^{40}$ have evaluated the combination of gefitinib and cetuximab in a panel of human cancer cell lines and in an EGFR-dependent human tumor xenograft model (A431). The combined treatment with the two agents resulted in a synergistic effect on cell proliferation, a greater inhibition of EGFR-depending signal and induction of apoptosis. In in vivo experiments single agent gefitinib or cetuximab induced transient complete remission only at the highest doses, while suboptimal doses of both drugs given in combination induced complete and permanent regression of large tumors with a greater inhibition of EGFR, MAP-K, and AKT phosphorylation. The evaluation of cDNA arrays showed that while 59 genes were coregulated by the two agents, 45 genes were differentially regulated, strengthening the rationale of the combined administration. Huang and colleagues $^{41}$ evaluated the potency of EGFR inhibition in a variety of human cancer cell lines after treatment with combination of cetuximab and either gefitinib or erlotinib. The combination enhanced growth inhibition over that observed with either single agent alone. In vivo data confirmed that higher tumor regression and growth delays were observed in mice treated with the combination. Taken as a whole, these studies may pave the way to clinical evaluation of combinations of EGFR-targeted agents.

Simultaneous targeting of multiple pathways is an attractive strategy of cancer treatment. In particular, the combined use of drugs targeting EGFR and vascular endothelial growth factor (VEGF) pathways is an appealing approach since angiogenesis has been associated with tumor progression and worse outcomes. Furthermore VEGF is often upregulated in tumors resistant to anti-EGFR compounds. Most of the clinical studies which have been run with the combination of anti-EGFR and anti-VEGF compounds have involved erlotinib and bevacizumab. However, early results of a clinical trial involving the combination of cetuximab and bevacizumab have been presented in patients with recurrent/metastatic SCCHN that had progressed after a prior line of chemotherapy. ${ }^{42}$ This combination showed a good clinical activity with a disease control rate of $80 \%$. Further trials are needed to confirm this encouraging result. 
Table 2 Ongoing clinical trials with cetuximab in SCCHN

\begin{tabular}{|c|c|c|c|c|c|c|}
\hline Trial & N. patients & Phase & Design & Endpoints & Results & Setting \\
\hline Kies et $\mathrm{al}^{33}$ & 47 & II & CBDCA-paclitaxel-cetuximab (induction) & CRR & $27 \%$ & $\begin{array}{l}\text { Locally advanced } \\
\text { disease }\end{array}$ \\
\hline Tishler et $\mathrm{al}^{35}$ & 15 & I & $\begin{array}{l}\text { CDDP-docetaxel-5FU + cetuximab 5FU } \\
\text { excalating dose } 750 \rightarrow 1000 \mathrm{mg} / \mathrm{m}^{2} \text { (induction) }\end{array}$ & ORR & $73 \%$ & $\begin{array}{l}\text { Locally advanced } \\
\text { disease }\end{array}$ \\
\hline Kuperman et a ${ }^{36}$ & 21 & II & $\begin{array}{l}\text { CDDP-docetaxel-5FU + cetuximab } \\
\text { (induction) }\end{array}$ & ORR & $71 \%$ & $\begin{array}{l}\text { Locally advanced } \\
\text { disease }\end{array}$ \\
\hline Argiris et $\mathrm{al}^{37}$ & 37 & II & $\begin{array}{l}\text { CDDP-docetaxel + cetuximab (induction) } \\
\text { followed by CDDP + radiotherapy }\end{array}$ & ORR & $100 \%$ & $\begin{array}{l}\text { Locally advanced } \\
\text { disease }\end{array}$ \\
\hline Langer et $\mathrm{al}^{38}$ & 61 & II & Radiotherapy-CDDP + cetuximab & ORR & $48 \%$ & $\begin{array}{l}\text { Locally advanced } \\
\text { disease }\end{array}$ \\
\hline Bonnin et $\mathrm{al}^{39}$ & 123 & II & $\begin{array}{l}\text { CDDP-docetaxel-5FU followed by } \\
\text { radiotherapy-CDDP + cetuximab }\end{array}$ & ORR & $96 \%$ & $\begin{array}{l}\text { Locally advanced } \\
\text { disease }\end{array}$ \\
\hline
\end{tabular}

Abbreviations: CRR, complete response rate; DCR, disease control rate; ORR, overall response rate.

Finally, the relationship between the RAS gene family, particularly K-ras, and tumorigenesis has generated considerable interest. In particular, the occurrence of K-ras mutation has been associated with the effectiveness of cetuximab and other drugs interfering with EGFR signaling in advanced colorectal cancer..$^{43}$ As for head and neck cancer, overexpression and mutation of members of the RAS gene family have been observed more rarely, ${ }^{44}{ }^{45}$ but clinical trials in this setting are well worth undertaking.

\section{Disclosures}

The authors report no conflicts of interest in this work.

\section{References}

1. El-Rayes BF, LoRusso PM. Targeting the epidermal growth factor receptor. Br J Cancer. 2004;91:418-424.

2. Kalyankrishna S, Grandis JR. Epidermal growth factor receptor biology in head and neck cancer. J Clin Oncol. 2006;24:2666-2672.

3. Rubin Grandis J, Melhem MF, Gooding WE, et al. Levels of TGF-a and EGFR protein in head and neck squamous cell carcinoma and patient survival. J Natl Cancer Inst. 1998;90:824-832.

4. Chung CH, Ely K, McGavran L, et al. Increased epidermal growth factor receptor gene copy number is associated with poor prognosis in head and neck squamous cell carcinoma. J Clin Oncol. 2006;24:4170-4176.

5. Temam S, Kawaguchi H, El-Naggar AK, et al. Epidermal growth factor receptor copy number alterations correlate with poor clinical outcome in patients with head and neck squamous cell cancer. J Clin Oncol. 2007;25:2164-2170.

6. Bandrés E, Barricarte R, Cantero C, et al. Epidermal growth factor receptor (EGFR) polymorphisms and survival in head and neck cancer patients. Oral Oncol. 2007;43:713-719.

7. Baselga J, Pfister D, Cooper MR, et al. Phase I studies of anti-epidermal growth factor receptor chimeric antibody C225 alone and in combination with cisplatin. J Clin Oncol. 2000;18:904-914.

8. Shin DM, Donato NJ, Perez-Soler R, et al. Epidermal growth factor receptor-targeted therapy with $\mathrm{C} 225$ and cisplatin in patients with head and neck cancer. Clin Cancer Res. 2001;7:1204-1213.

9. NCCN Clinical Practice Guidelines in Oncology. Latest update date and version number 2007-2008. [Cited July 27, 2009]. Available from: http://www.nccn.org/professionals/physician_gls/f_guidelines.asp.
10. Burtness B, Goldwasser MA, Flood W, Mattar B, Forastiere AA; Eastern Cooperative Oncology Group. Phase III randomized trial of cisplatin plus placebo compared with cisplatin plus cetuximab in metastatic/ recurrent head and neck cancer: an eastern cooperative oncology group study. J Clin Oncol. 2005;23:8646-8653.

11. Bourhis J, Rivera F, Mesia R, et al. Phase I/II study of cetuximab in combination with cisplatin or carboplatin and fluorouracil in patients with recurrent or metastatic squamous cell carcinoma of the head and neck. J Clin Oncol. 2006;24:2866-2872.

12. Vermorken JB, Mesia R, Rivera F, et al. Platinum-based chemotherapy plus cetuximab in head and neck cancer. $N$ Engl J Med. 2008;359: 1116-1127.

13. Herbst RS, Arquette M, Shin DM, et al. Phase II multicenter study of the epidermal growth factor receptor antibody cetuximab and cisplatin for recurrent and refractory squamous cell carcinoma of the head and neck. J Clin Oncol. 2005;23:5578-5587.

14. Baselga J, Trigo JM, Bourhis J, et al. Phase II multicenter study of the antiepidermal growth factor receptor monoclonal antibody cetuximab in combination with platinum based chemotherapy in patients with platinum refractory metastatic and or recurrent squamous cell carcinoma of the head and neck. J Clin Oncol. 2005;23:5568-5576.

15. Vermorken JB, Trigo J, Hitt R, et al. Open-label, uncontrolled, multicenter, phase II study to evaluate the efficacy and toxicity of cetuximab as a single agent in patients with recurrent and or metastatic squamous cell carcinoma of the head and neck who failed to respond to platinum-based therapy. J Clin Oncol. 2007;25: 2171-2177.

16. Knoedler M, Gauler TC, Matzdorff A, et al. Phase II trial to evaluate efficacy and toxicity of cetuximab plus docetaxel in platinum pretreated patients with recurrent and/or metastatic head and neck cancer [abstract]. J Clin Oncol. 2008;26(Suppl 15):6066.

17. Buentzel J, De Vries A, Micke O. Experience with cetuximab plus paclitaxel/carboplatinum in primary platinum-resistant recurrent head and neck cancer. J Clin Oncol. 2007;25(Suppl 18):6077.

18. Pignon JP, Bourhis J, Domenge C, Designé L. Chemotherapy added to locoregional treatment for head and neck squamous-cell carcinoma: three meta-analyses of updated individual data. MACH-NC Collaborative Group. Meta-Analysis of Chemotherapy on Head and Neck Cancer. Lancet. 2000;355(9208):949-955.

19. Bernier J, Domenge C, Ozsahin M, et al. Postoperative irradiation with or without concomitant chemotherapy for locally advanced head and neck cancer. N Engl J Med. 2004;350(19):1945-1952.

20. Withers HR, Taylor JM, Maciejewski B. The hazard of accelerated tumor clonogen repopulation during radiotherapy. Acta Oncol. 1988;27:131-146. 
21. Ng CE, Keng PC, Sutherland RM. Characterization of radiation sensitivity of human squamous carcinoma A431 cells. Br J Cancer. 1987;56:301-307.

22. Peter RU, Beetz A, Ried C, Michel G, van Beuningen D, Ruzicka T. Increased expression of the epidermal growth factor receptor in human epidermal keratinocytes after exposure to ionizing radiation. Radiat Res. 1993;136:65-70.

23. Schmidt-Ullrich RK, Mikkelsen RB, Dent P, et al. Radiation induced proliferation of the human A431 squamous carcinoma cells is dependent on EGFR tyrosine phosphorylation. Oncogene. 1997;15: 1191-1197.

24. Saleh MN, Raisch KP, Stackhouse MA, et al. Combined modaliy therapy of A431 human epidermoid cancer using anti-EGFR antbody C225 and radiation. Cancer Biother Radiopharm. 1999;14: 451-463.

25. Robert F, Ezekiel MP, Spencer SA, et al. Phase I study of anti-epidermal growth factor receptor antibody cetuximab in combination with radiation therapy in patients with advanced head and neck cancer. J Clin Oncol. 2009;19:3234-3243.

26. Bonner JA, Harari PM, Giralt J, et al. Radiotherapy plus cetuximab for squamous cell carcinoma of the head and neck. $N$ Engl $J$ Med. 2006;354:567-578.

27. Curran D, Giralt J, Harari PM. Quality of life in head and neck cancer patients after treatment with high-dose radiotherapy alone or in combination with cetuximab. J Clin Oncol. 2007;10: 2191-2198.

28. Pfister DG, Su YB, Kraus DH, et al. Concurrent cetuximab, cisplatin and concomitant boost radiotherapy for locoregionally advanced squamous cell head and neck cancer: a pilot phase II study of a new combined modality paradigm. J Clin Oncol. 2006;7:1072-1078.

29. Merlano MC, Numico G, Russi EG, et al. Cetuximab (C-mab) and chemo-radiation (CT-RT) for loco-regional advanced squamous cell carcinoma of the head and neck (HNC): A phase II study [abstract]. J Clin Oncol. 2007;25(Suppl 18):6043.

30. Kuhnt T, Sandner A, Wendt TG, et al. Concomitant hyperfractionated accelerated radiotherapy (HART) with cisplatin and concurrent cetuximab for locoregionally advanced squamous cell head and neck cancer: a phase I dose escalation trial [abstract]. J Clin Oncol. 2008;26(Suppl 15):6029.

31. Vermorken JB, Remenar E, van Herpen C, et al. Cisplatin, fluorouracil and docetaxel in unresectable head and neck cancer. $N$ Engl $J$ Med. 2007;357(17):1695-1704.

32. Posner MR, Hershock DM, Blajman CR, et al; TAX 324 Study Group. Cisplatin and fluorouracil alone or with docetaxel in head and neck cancer. N Engl J Med. 2007;357(17):1705-1715.

33. Kies MS, Garden AS, Holsinger C, et al. Induction chemotherapy (CT) with weekly paclitaxel, carboplatin and cetuximab for squamous cell carcinoma of the head and neck [abstract]. J Clin Oncol. 2006; 24(Suppl 18):5520.
34. Wanebo HJ, Ghebremichael M, Burtness B, et al. Phase II evaluation of C225 combined with induction paclitaxel and carboplatin followed by $\mathrm{C} 225$, paclitaxel, and radiation for Stage III/IV operable squamous cancer of the head and neck: A trial of the Eastern Cooperative Oncology Group (ECOG E2303) [abstract]. J Clin Oncol. 2007;25(Suppl 18):6015.

35. Tishler RB, Posner MR, Wirth LJ, et al. Cetuximab added to docetaxel, cisplatin, 5-fluorouracil Induction chemotherapy (C-TPF) in patients with newly diagnosed locally advanced head and neck cancer: A phase I study [abstract]. J Clin Oncol. 2008;26(Suppl 15):6001.

36. Kuperman DI, Nussenbaum B, Thorstad W, Haughey B, Lewis J, Adkins D. Retrospective analysis of the addition of cetuximab to induction chemotherapy (IC) with docetaxel, cisplatin, and 5-fluorouracil (TPF-C) for locally advanced squamous cell carcinoma of the head and neck (LA-HNSCC) [abstract]. J Clin Oncol. 2007;25(Suppl 18):6072.

37. Argiris AE, Karamouzis MV, Heron DE, et al. Phase II trial of docetaxel $(\mathrm{T})$, cisplatin $(\mathrm{P})$, and cetuximab (E) followed by concurrent radiation (RT), P, and E in locally advanced head and neck squamous cell carcinoma (HNSCC) [abstract]. J Clin Oncol. 2007;25(Suppl 18):6051.

38. Langer J, Lee JW, Patel UA, et al. Preliminary analysis of ECOG 3303: Concurrent radiation, cisplatin and cetuximab in unresectable, locally advanced squamous cell carcinoma of the head and neck (SCCHN). J Clin Oncol. 2008;26(Suppl 15):6006.

39. Bonnin N, Ceruse P, Bachelot T, et al. Efficacy of neoadjuvant TPF (nTPF; docetaxel, T; cisplatin, $\mathrm{P}$; 5FU) in nonselected patients (pts) with head and neck cancer and subsequent radiotherapy (RT) combined with chemotherapy (CT) or cetuximab (Cx) [abstract]. J Clin Oncol. 2008;26(Suppl 15):6074.

40. Matar P, Rojo F, Cassia R, et al. Combined epidermal growth factor receptor targeting with the tyrosine kinase inhibitor gefitinib (ZD1839) and the monoclonal antibody cetuximab (IMC-C225): superiority over single-agent receptor targeting. Clin Cancer Res. 2004;10(19):6487-6501.

41. Huang S, Armstrong EA, Benavente S, Chinnaiyan P, Harari PM. Dual-agent molecular targeting of the epidermal growth factor receptor (EGFR): combining anti-EGFR antibody with tyrosine kinase inhibitor. Cancer Res. 2004;64(15):5355-5362.

42. Kies S, Gibson MK, Kim SW, et al. Cetuximab (C) and bevacizumab (B) in patients with recurrent or metastatic head and neck squamous cell carcinoma (SCCHN): An interim analysis. J Clin Oncol. 2008; 26(Suppl 15):6072.

43. Karapetis CS, Khambata-Ford S, Jonker DJ, et al. K-ras mutations and benefit from cetuximab in advanced colorectal cancer. New Engl J Med. 2008;359:1757-1765.

44. Yarbrough WG, Shores C, Witsell DL, Weissler MC, Fidler ME, Gilmer TM. Ras mutations and expression in head and neck squamous cell carcinomas. Laryngoscope. 1994;104:1337-1347.

45. Rathcke IO, Gottschlinch S, Görögh T, Lippert BM, Werner JA. Incidence of point mutations in Ki-ras codon 12 and 13 in squamous epithelial carcinomas of the head and neck region. Laryngorhinootologie. $1996 ; 75: 465-470$.
OncoTargets and Therapy

\section{Publish your work in this journal}

OncoTargets and Therapy is an international, peer-reviewed, open access journal focusing on the pathological basis of all cancers, potential targets for therapy and treatment protocols employed to improve the management of cancer patients. The journal also focuses on the impact of management programs and new therapeutic agents and protocols on
Dovepress

patient perspectives such as quality of life, adherence and satisfaction The manuscript management system is completely online and includes a very quick and fair peer-review system, which is all easy to use. Visit http://www.dovepress.com/testimonials.php to read real quotes from published authors. 